\title{
Respiratory syncytial virus hospitalization trends in infants with chronic lung disease of infancy, 1998-2008
}

This article was published in the following Dove Press journal:

Clinical Epidemiology

28 September 2011

Number of times this article has been viewed

\author{
Jessie R Groothuis' \\ Jon P Fryzek ${ }^{1,2}$ \\ Doris Makari' \\ Duane Steffey ${ }^{2}$ \\ William J Martone'
}

'Medlmmune, LLC, Gaithersburg, MD,

${ }^{2}$ Exponent, Menlo Park, CA, USA
Correspondence: Jessie R Groothuis One Medlmmune Way, Gaithersburg, MD 20878, USA

$\mathrm{Tel}+\mathrm{I} 30|3984| 58$

$\mathrm{Fax}+\mathrm{I} 3013989158$

Email groothuisj@medimmune.com
Objective: Infants with chronic lung disease of infancy (CLDI) are at high risk for severe respiratory syncytial virus (RSV) illness requiring hospitalization. Palivizumab was first licensed in 1998 for the prevention of RSV disease in high-risk infants, including those with CLDI. We performed a retrospective cohort study of all hospitalized children with CLDI aged $<2$ years between 1998 and 2008 in the USA to determine trends in rates of hospitalizations due to RSV (RSVH) since the launch of palivizumab.

Materials and methods: Data from the United States National Hospital Discharge Survey, a multistage systematic survey sample of US hospitals, were assembled. We defined RSVH using International Classification of Diseases, Ninth Revision, Clinical Modification (ICD-9-CM) codes of 079.6 (RSV), 466.11 (acute bronchiolitis due to RSV), and 480.1 (pneumonia due to RSV). Quarterly rates of RSVH were assessed for children with CLDI (ICD-9-CM code 770.7) and calculated between 1998 and 2008. Because RSV may be miscoded, the analysis was repeated after expanding the definition of RSVH to include all acute bronchitis and acute bronchiolitis $(\mathrm{ABH})(\mathrm{ICD}-9-\mathrm{CM}=466)$. Trends were described using linear regression with seasonal indicators included in the model.

Results: On average, about 966 RSVH (range 98-1373 RSVH) per year were found for children $<2$ years with CLDI in the USA between 1998 and 2008. Over the 11-year period, the predicted rate of RSVH statistically significantly decreased by $48 \%$ (from 93.78 to $49.06 \mathrm{RSVH}$ per 1 million children $(P=0.013)$. Addition of ABH resulted in a nonstatisically significant decrease of $32 \%$ over the 10 -year period $(P=0.102)$.

Conclusion: These results suggest that there has been a decrease in the rate of RSVH in infants with CLDI between 1998 and 2008. The reasons for this decrease may include improved neonatal intensive care unit and outpatient management of CLDI, and possibly increased use of palivizumab in this high-risk population.

Keywords: bronchiolitis, CLDI, RSV, palivizumab

\section{Introduction}

Chronic lung disease of infancy (CLDI), as defined by the American Thoracic Society, ${ }^{1}$ is "a heterogeneous group of respiratory diseases of infancy that usually evolves from an acute respiratory disorder experienced by a newborn infant." CLDI occurs most frequently in infants born prematurely and is the most common form of chronic lung disease of infancy in the USA. ${ }^{2}$ Infants with CLDI are at high risk for re-hospitalization in the first 2 years of life, and in particular, are at high risk for RSVH (hospitalization due to lower respiratory tract infection due to respiratory syncytial virus $[\mathrm{RSV}]) .^{3}$ 
Palivizumab (MedImmune, LLC, Gaithersburg, MD), a humanized monoclonal antibody developed for the prevention of RSV disease in high-risk infants, has been recommended since 1998 for infants and young children with CLDI who are $\leq 24$ months of age. ${ }^{4}$ To our knowledge, no studies have evaluated RSV/bronchiolitis hospitalizations in infants and children with CLDI after palivizumab became available. We analyzed data from the United States National Hospital Discharge Survey (NHDS) to examine temporal trends in RSVHs among children younger than 2 years following the introduction of palivizumab.

\section{Materials and methods}

Data from the NHDS for children younger than 2 years with a diagnosis of CLDI were analyzed to examine the rate of hospitalizations for CLDI (CLDIH) that were also associated with RSV for each year between 1998 and 2008. US population values for children $<2$ years used to calculate yearly rates were available through CDC WONDER. ${ }^{5}$ Because testing for RSV is not consistently performed in the hospital setting, we repeated the analyses with an expanded definition of RSV that included acute bronchitis and bronchiolitis.

The NHDS is the largest available nationally representative survey of inpatient hospitalizations. NHDS has been collecting inpatient discharge records from nonfederal short-stay hospitals annually since 1965. Patient discharges from hospitals having six or more beds for inpatient use are included in the survey. A three-stage probability design based on geographic areas, hospitals, and discharges is utilized to select sample data. Data are weighted to produce national estimates. Variables collected at each discharge included patient demographics (age, sex, race, marital status), hospital characteristics (geographic location, number of beds), and inpatient hospitalization diagnoses (up to seven ICD-9-coded diagnoses), days of hospitalized care, patient disposition, month, day, and year of discharge, primary and secondary expected source of payment, and type of admission and procedures. Patient identification information is removed so that all data are anonymous. $^{6}$

Hospital discharges with $\geq 1$ diagnosis coded to ICD-9 770.7 were considered CLDIHs. This code covers CLDI arising in the perinatal period, and includes bronchopulmonary dysplasia, interstitial pulmonary fibrosis of prematurity, and Wilson-Mikity syndrome. ${ }^{7}$ RSV associated with CLDIH (RSVH) was defined as a hospital discharge with a diagnosis code of 770.7 (chronic lung disease) and a diagnosis code of 079.6 (RSV), 466.11 (acute bronchiolitis due to RSV) or 480.1 (pneumonia due to RSV). Although RSV coding was first introduced in 1996, the current study analyzed data starting in 1998 to allow enough time to ensure wide hospital adoption of the new RSV codes.

Testing for RSV is often not performed in the hospital setting and presumptive RSV lower respiratory infections may be miscoded. We therefore expanded our definition of RSVH to include all acute bronchitis and acute bronchiolitis hospitalizations (ABHs) and conducted additional analyses based on this expanded definition of disease (RSVH/ABH). Specifically, a hospital discharge with an ICD-9 diagnosis code of 770.7 (CLDI) and a diagnosis code of either 079.6 (RSV), or 480.1 (pneumonia due to RSV) or any 466 (acute bronchitis and bronchiolitis) were considered together as RSVH/ABH. ICD-9 diagnosis code 466 includes 466.0 (acute bronchitis), 466.1 (acute bronchiolitis), 466.11 (acute bronchiolitis due to RSV), and 466.19 (acute bronchiolitis due to other organisms).

Analyses were limited to hospitalization discharges that occurred prior to a child with CLDIH turning 2 years old. Simple descriptive statistics were calculated. Quarterly rates of RSVH (or RSVH/ABH) among children with CLDI were calculated by dividing the number of RSVH (or RSVH/ $\mathrm{ABH}$ ) among children with CLDI by the total number of children for that year. Data were first transformed using the square root to correct for heteroscedasticity. ${ }^{8}$ Indicator variables corresponding to each quarter of the year were created to control for seasonality. ${ }^{9}$ Trends were described using linear regression. All statistical analyses were performed using Statistical Analysis Software version 9.1 (SAS Institute Inc, Cary, NC) and Minitab Statistical Software (Minitab Inc, Release 14, State College, PA). The figures displaying actual rates versus predicated rates of RSVH and RSVH/ABH (Figures 1 and 2) were produced using Minitab Statistical Software Release 14 (Minitab Inc, State College, PA).

\section{Results}

From 1998 to 2008, there were 10,622 CLDI children with RSVH. The primary hospitalization for RSVH (first diagnosis code of the up to 7 discharge diagnosis codes listed) was acute bronchitis and bronchiolitis (ICD-9 = 466) (60\%) for most of the CLDI children followed by viral pneumonia $($ ICD-9 = 480) $(17 \%)$, asthma $($ ICD-9 = 493) $(5 \%)$, pneumonia $($ ICD-9 $=486)(3 \%)$, and other conditions (15\%). Forty-five percent of RSVHs were found in children $>6$ months to 2 years. RSVH was more common 


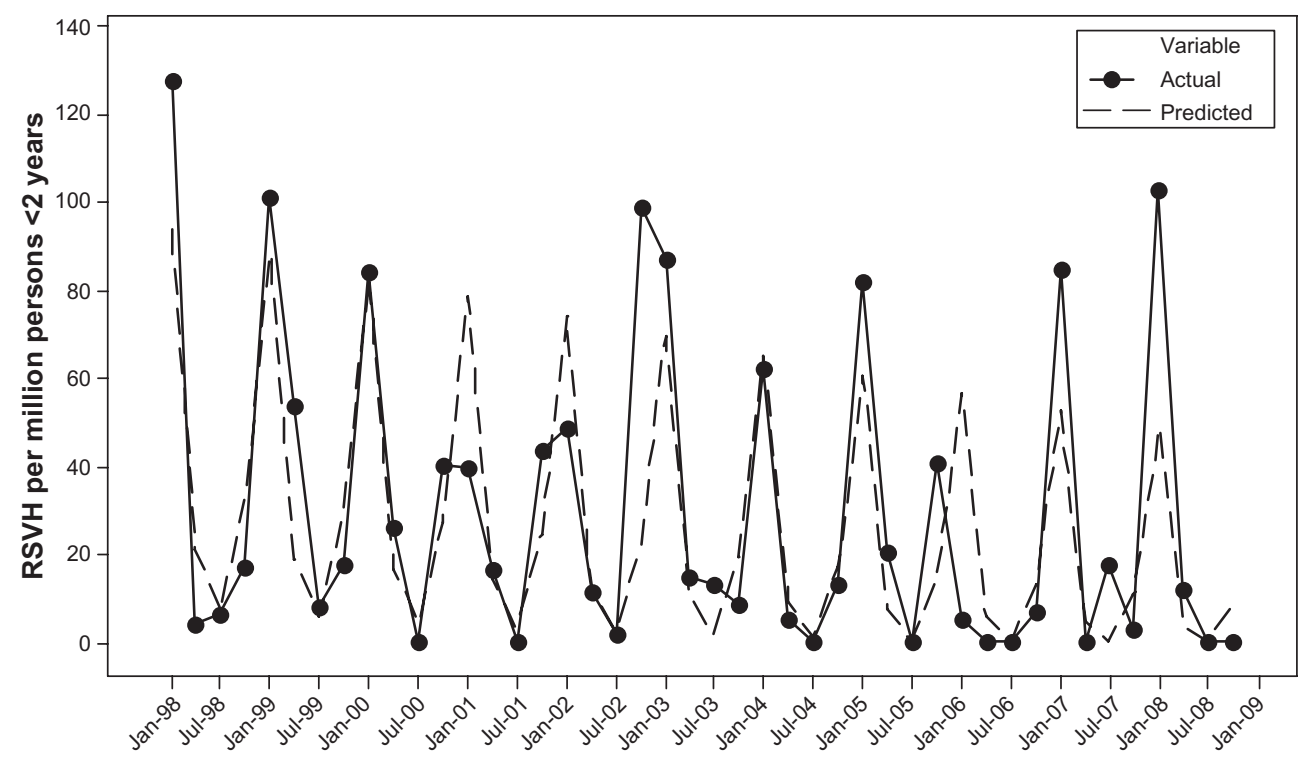

Figure I The rates of respiratory syncytial virus hospitalizations among patients younger than 2 years with CLDI by quarter from 1998 to 2008 . Actual rates and predicted rates from time series regression model.

Abbreviations: CLDI, chronic lung disease of infancy; RSV, respiratory syncytial virus; RSVH, respiratory syncitial virus hospitalization.

among males (65\%) (Table 1). By race, $44 \%$ of RSVH occurred among whites, compared with $25 \%$ among African Americans and 31\% among others/unknown. By region, more RSVHs occurred in the Western part of the USA $(39 \%)$ than in the Midwest (22\%) or Northeast (23\%), with the lowest percentage of RSVHs occurring in the South
$(16 \%)$. Medicaid was the expected source of payment for the majority of RSVHs (64\%).

RSVH/ABH included 23,199 hospitalizations, of which 21,780 hospitalizations were due to ICD-9 code 466. Among those with ICD-9 code 466, $2 \%$ were coded as acute bronchitis (ICD-9 $=466.0), 42 \%$ were coded as acute bronchiolitis

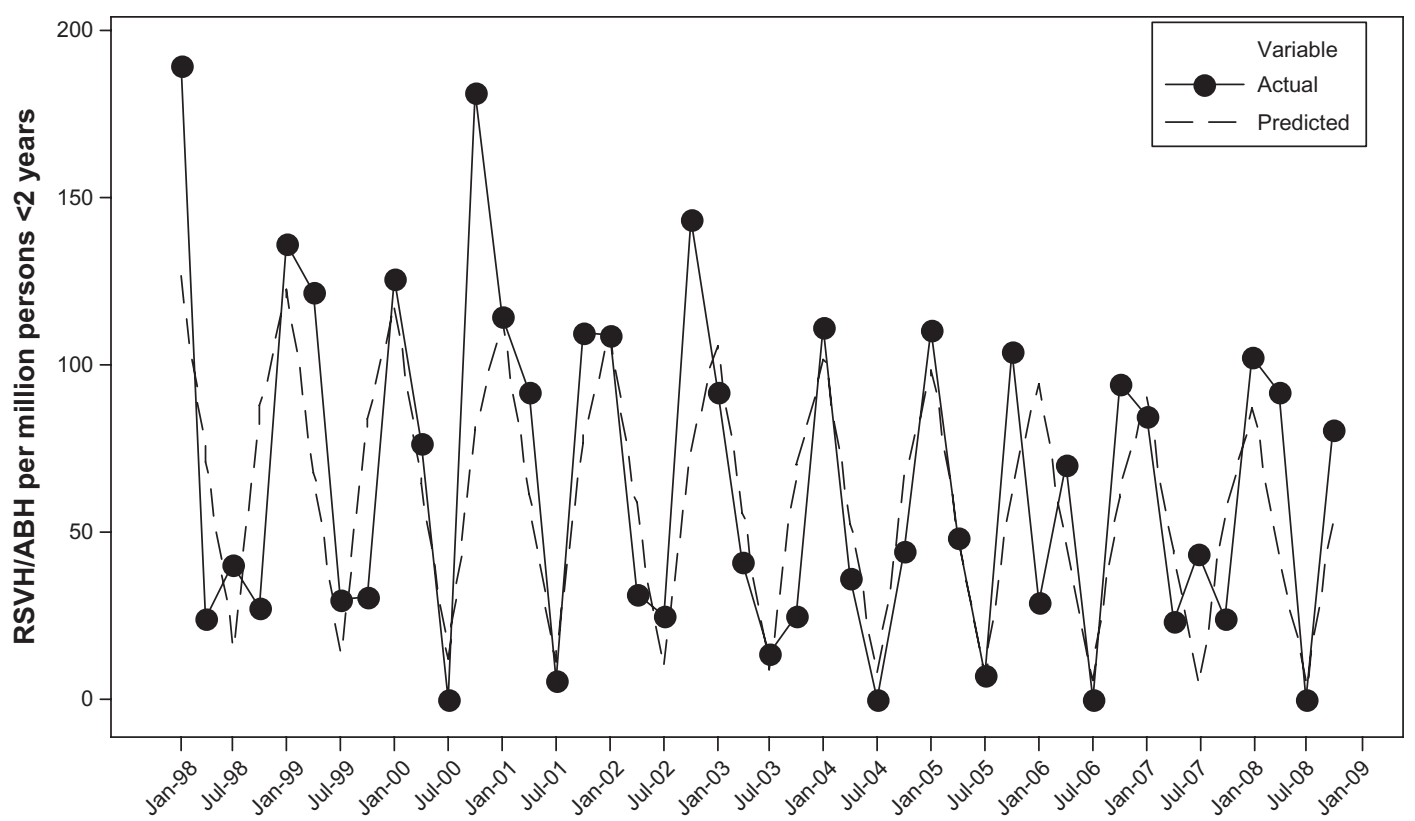

Figure 2 The rates of respiratory syncytial virus and AB and bronchiolitis hospitalizations among patients younger than 2 years with CLDI by quarter from I998 to 2008 . Actual rates and predicted rates from time series regression model.

Abbreviations: $A B$, acute bronchitis; CLDI, chronic lung disease of infancy; RSV, respiratory syncytial virus; RSVH, respiratory syncitial virus hospitalization. 
Table I Characteristics of CLDI children younger than 2 years with RSVH or RSVH/ABH between 1998 and 2008, National Hospital Discharge Survey

\begin{tabular}{|c|c|c|c|c|}
\hline & \multicolumn{2}{|l|}{ RSVH } & \multicolumn{2}{|c|}{ RSVH/ABH } \\
\hline & Number & Percentage $^{a}$ & Number & Percentage \\
\hline \multicolumn{5}{|l|}{ Age } \\
\hline$<3$ months & 2426 & $23 \%$ & 3323 & $14 \%$ \\
\hline 3-6 months & 3404 & $32 \%$ & 10,035 & $44 \%$ \\
\hline$>6$ months & 4792 & $45 \%$ & $984 I$ & $42 \%$ \\
\hline \multicolumn{5}{|l|}{ to $<2$ years } \\
\hline \multicolumn{5}{|l|}{ Gender } \\
\hline Male & 6922 & $65 \%$ & 14,640 & $63 \%$ \\
\hline Female & 3700 & $35 \%$ & 8559 & $37 \%$ \\
\hline \multicolumn{5}{|l|}{ Race } \\
\hline White & 4696 & $44 \%$ & 10,615 & $46 \%$ \\
\hline Black & 2670 & $25 \%$ & 5245 & $23 \%$ \\
\hline Other/ & 3256 & $31 \%$ & 7339 & $32 \%$ \\
\hline \multicolumn{5}{|l|}{ Unknown } \\
\hline \multicolumn{5}{|l|}{ Region } \\
\hline Northeast & 2494 & $23 \%$ & 5294 & $23 \%$ \\
\hline Midwest & 2290 & $22 \%$ & 6915 & $30 \%$ \\
\hline South & $|70|$ & $16 \%$ & 3486 & $15 \%$ \\
\hline West & 4137 & $39 \%$ & 7504 & $32 \%$ \\
\hline \multicolumn{5}{|l|}{ Medicaid } \\
\hline Yes & 6759 & $64 \%$ & 16,402 & $71 \%$ \\
\hline No & 3863 & $36 \%$ & 6797 & $29 \%$ \\
\hline Total & 10,622 & $100 \%$ & 23,199 & $100 \%$ \\
\hline
\end{tabular}

Note: ${ }^{a}$ Totals may not equal $100 \%$ due to rounding.

Abbreviations: CLDI, chronic lung disease of infancy; RSVH, respiratory syncitial virus hospitalization; $\mathrm{RSVH} / \mathrm{ABH}$, respiratory syncitial virus and acute bronchitis and acute bronchiolitis hospitalization.

due to respiratory syncitial virus (ICD-9 $=466.11$ ), and 56\% were coded as acute bronchiolitis due to other infectious organisms (ICD-9 = 466.19). The demographics for patients with RSVH/ABH were similar to those patients with RSVH (Table 1).

The average annual number of CLDIH was 22,937 (range 17,169-26,130) and the mean annual number of RSVH was 966 (range 98-1373) (Figure 3). The number of CLDIHs peaked in 2002, and the number of RSVHs peaked in 1999. The proportion of all-cause hospital admissions in infants and children with CLDI did not change significantly over this time period $(P=0.146)$ (Figure 3$)$.

The predicted rates are based on the fitted regression model with linear time trend and seasonal indicator terms. The predicted rate of RSVH among children with CLDI in the first quarter of 1998 is 93.78 per million children, while the predicted rate of RSVH in the first quarter of 2008 is 49.06 . Over the 11-year period, the predicted rate of RSVH dropped significantly by $48 \%(P=0.013)$ (Figure 1$)$. The predicted rate of RSVH/ABH declined by $32 \%$ over the 11-year period, though this was not statistically significant $(P=0.102)$ (Figure 2).

\section{Discussion}

CLDI is the most common form of chronic lung disease in children in the USA. ${ }^{1}$ Northway and coworkers first described CLDI, which they called bronchopulmonary dysplasia, in 19 preterm infants who were born at approximately 32 weeks gestation and weighed a mean of 2000 g. ${ }^{10}$ In the ensuing four decades a variety of measures to prevent and treat respiratory distress syndrome and CLDI in premature infants (eg, antenatal steroids, surfactant replacement, and a more conservative approach to respirator support) have been introduced. ${ }^{1}$ These improvements have resulted in changes in the clinical and pathologic characteristics of pulmonary involvement but have not produced a decrease in CLDI or CLDIHs, primarily because increasingly smaller premature infants are surviving. The average gestational age and birth weight of premature infants with CLDI has continued to decrease over the past four decades to a mean gestational age of 27 weeks and a birth weight of $<1000 \mathrm{~g}$. ${ }^{1}$ The findings from this 11-year cohort study suggest that RSVHs in children younger than 2 years with CLDI have steadily decreased even while all-cause hospitalizations in this highrisk population remained unchanged.

Because RSV testing is not performed in up to $30 \%$ of suspected RSV cases, ${ }^{11}$ we re-analyzed the data using an expanded definition of disease that included acute bronchitis and bronchiolitis. Using the expanded definition, we observed comparable (but not statistically significant) declines in annual rates of hospitalizations. Therefore, we found no evidence that potential misclassification of RSV or frequency of RSV testing played an important role in the trends we observed.

The reasons for the overall decrease in RSVHs/ABHs in infants with CLDI are not well understood and are probably multifactorial. Potential explanations include improved neonatal intensive care unit and outpatient management of CLDI, and increased public awareness with improved protection of these infants from RSV illness. The increased uptake of the recommendations of the Committee on Infectious Diseases for use of palivizumab in preterm infants with CLDI may also play a role. Palivizumab, used for immunoprophylaxis for the prevention of serious RSV disease, was first licensed in 1998. In a multinational, randomized, placebo-controlled study, palivizumab was observed to reduce RSVH in preterm infants with CLDI by $39 \%$. Common adverse events reported in this trial included fever, nervousness, injection site reaction, and diarrhea. ${ }^{12}$

The strengths of this study included its large sample size, record-based data collection, a broad geographic scope, and 


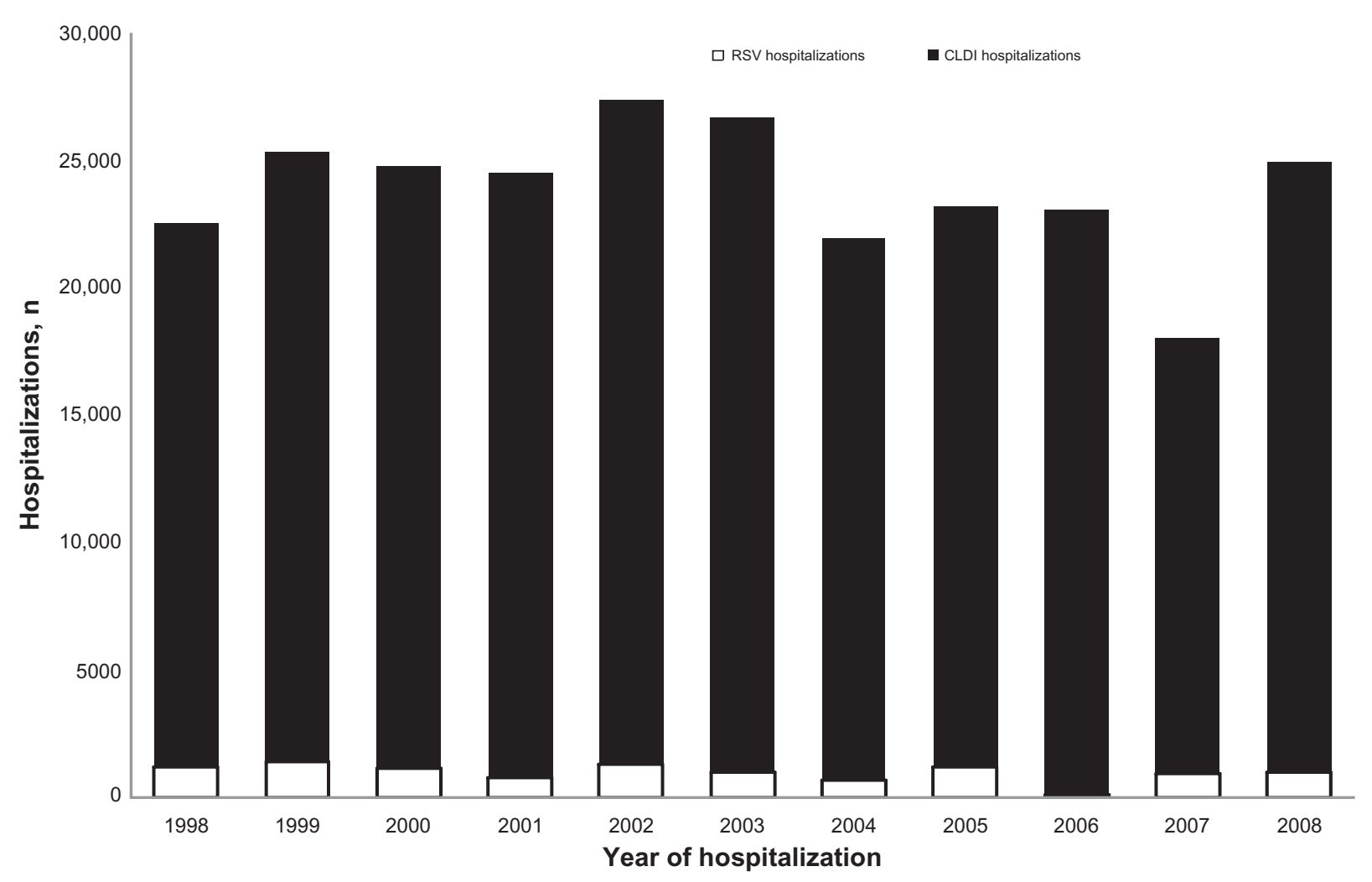

Figure 3 Number of hospitalizations for CLDI children younger than 2 years by year. Abbreviations: CLDI, chronic lung disease of infancy; RSV, respiratory syncytial virus.

a prolonged period of surveillance (11 respiratory disease seasons). Limitations included our inability to validate the type of RSV testing used to assign a diagnosis of RSV. However, a recent study determined that RSVH discharge data correlate well with RSV testing data, regardless of the type of testing used. ${ }^{13}$ While it is not completely certain what proportion of infants with CLDI receive palivizumab, recent data from Canadian and US registries suggest that palivizumab has been increasingly used for RSV prophylaxis in infants with CLDI since it was first launched in 1998. ${ }^{14,15}$

In conclusion, this study demonstrated a steady decrease in the yearly incidence rates of RSV-associated respiratory disease in infants and young children with CLDI over 11 successive respiratory disease seasons. Reasons for this decrease are most likely multifactorial. Further study is warranted to explore these findings.

\section{Acknowledgments}

The authors are employees of, or consultants to, MedImmune, the sponsor of the study. Editorial support (formatting and graphics development) provided by Complete Healthcare Communications, Inc (Chadds Ford, PA) was funded by MedImmune.

\section{Disclosure}

The authors report no conflicts of interest in this work.

\section{References}

1. Allen J, Zwerdling R, Ehrenkranz R, et al. Statement on the care of the child with chronic lung disease of infancy and childhood. Am J Respir Crit Care Med. 2003;168(3):356-396.

2. Baraldi E, Filippone M. Chronic lung disease after premature birth. N Engl J Med. 2007;357(19):1946-1955.

3. Groothuis JR, Gutierrez KM, Lauer BA. Respiratory syncytial virus infection in children with bronchopulmonary dysplasia. Pediatrics. 1988; 82(2):199-203.

4. Prevention of respiratory syncytial virus infections: indications for the use of palivizumab and update on the use of RSV-IGIV. American Academy of Pediatrics Committee on Infectious Diseases and Committee of Fetus and Newborn. Pediatrics. 1998;102(5):1211-1216.

5. United States Department of Health and Human Services (US DHHS), Centers for Disease Control and Prevention (CDC), National Center for Health Statistics (NCHS), Bridged-Race Population Estimates, United States July 1 st resident population by state, county, age, sex, bridged-race, and Hispanic origin, compiled from 1990-1999 bridged-race intercensal population estimates and 2000-2009 (Vintage 2009) bridged-race postcensal population estimates, on CDC WONDER On-line Database. Available from: http://wonder.cdc.gov/bridged-race-v2009.html. Accessed April 1, 2011

6. Dennison C, Pokras R. Design and operation of the National Hospital Discharge Survey: 1988 redesign. Vital Health Stat 1. 2000;39:1-42.

7. Practice Management Information Corporation. International Classification of Diseases, 9th Revision, Clinical Modification. 4th ed. Practice Management Information Corporation; 2006. 
8. Draper NR, Smith H. Applied Regression Analysis. 2nd ed. New York, NY: Wiley; 1981.

9. Bowerman BL, O'Connell RT, Koehler AB. Forecasting, Time Series, and Regression. 4th ed. Belmont, CA: Thomson Brooks/Cole; 2005.

10. Northway WH Jr, Rosan RC, Porter DY. Pulmonary disease following respirator therapy of hyaline-membrane disease. Bronchopulmonary dysplasia. N Engl J Med. 1967;276(7):357-368.

11. Hall CB, Weinberg GA, Iwane MK, et al. The burden of respiratory syncytial virus infection in young children. NEngl J Med. 2009;360(6): 588-598.

12. The IMpact-RSV Study Group. Palivizumab, a humanized respiratory syncytial virus monoclonal antibody, reduces hospitalization from respiratory syncytial virus infection in high-risk infants. Pediatrics. 1998;102(3 Pt 1):531-537.
13. Light M, Bauman J, Mavunda K, Malinoski F, Eggleston M. Correlation between respiratory syncytial virus (RSV) test data and hospitalization of children for RSV lower respiratory tract illness in Florida. Pediatr Infect Dis J. 2008;27(6):512-518.

14. Mitchell I, Paes BA, Lanctot KL. CARRESS: the Canadian Registry of Palivizumab. Pediatr Infect Dis J. Epub 2011 Feb 18.

15. Frogel M, Nerwen C, Cohen A, et al. Prevention of hospitalization due torespiratory syncytial virus: results from the Palivizumab Outcomes Registry. J Perinatol. 2008;28:511-517.

\section{Publish your work in this journal}

Clinical Epidemiology is an international, peer-reviewed, open access journal focusing on disease and drug epidemiology, identification of risk factors and screening procedures to develop optimal preventative initiatives and programs. Specific topics include: diagnosis, prognosis, treatment, screening, prevention, risk factor modification, systematic

Submit your manuscript here: http://www.dovepress.com/clinical-epidemiology-journal

\section{Dovepress}

reviews, risk \& safety of medical interventions, epidemiology \& biostatical methods, evaluation of guidelines, translational medicine, health policies \& economic evaluations. The manuscript management system is completely online and includes a very quick and fair peer-review system, which is all easy to use. 